\title{
The Working Conditions Among Early Childhood Educators Who Have Worked in Both For-Profit and Non-Profit Childcare Centres
}

\author{
Christine Romain-Tappin ${ }^{1}$, Rachel Langford ${ }^{2}$ \\ Loyalist College ${ }^{1}$, Ryerson University ${ }^{2}$
}

\begin{abstract}
The working conditions of members from a professional association are required to adhere to high quality standards. Being members of the college of Early Childhood Educators (ECE), the question remains: what do the working conditions of ECEs exemplify about the professionalism of the early childhood education and care (ECEC) field? In an effort to build the professional state of the Canadian ECEC sector one must begin to critically examine the working conditions of ECEs. Efforts towards achieving professional status for all ECEs are evident in the working conditions they are provided, which may vary depending upon whose auspices they are under. This study examined ECEs' perceptions of the differences in working conditions between for profit and non-profit childcare centres in the Greater Toronto Area. Four ECEs who have worked in both for-profit and non-profit childcare centres were interviewed. In these interviews, the ECEs reported that non-profit childcare centres provide higher quality working conditions than for-profit childcare centres, demonstrating the value and support which an auspice has towards professionalism.
\end{abstract}

\section{Introduction}

Since early childhood education and care (ECEC) is currently a topic of discussion at the forefront of political agendas [1], so too should be the needs of its workforce. According to the Child Care Human Resources Sector Council (CCHRSC), early childhood educators (ECEs) are the single largest group in the ECEC sector with 170,340 ECEs and early childhood assistants (ECAs) in 2006. Only five years before, in 2001, there were 137,000 early childhood educators and assistants (ECEs/ECAs) working in both the regulated and unregulated childcare sector [2]. With the number of births rising $23 \%$ between 2000 and 2012 and the participation rate of women in the labour force with children under the age of 6 increasing more than $160 \%$ (from $30 \%$ in 1976 to $79 \%$ in 2012) [3] CCHRSC [2] reported a growth in the broader ECEC workforce of $24.9 \%$ between 2001 and 2006. Service Canada [3] predicts a significant increase in the number of early childhood educators in 2012 to 2016.

Clearly, ECEC is a growing field. Unfortunately, in spite of this growth, ECEs remain at the bottom of the labour force hierarchy because they are accorded very little respect [4]. ECEs play a vital role in the field of ECEC. However, professionalizing the field of childcare, as well as its practitioners, is considered a recent initiative. Many still do not consider the service as a profession [5]. And despite the abundance of studies emerging over the past few years regarding the importance of children's early years and the work that ECEs do, Canadians, policy makers, and politicians continue to "pay lip service only to the value of the work - working conditions and pay levels remain at very low levels" [4]. The work that ECEs do as professionals continues to be undervalued across Canada.

The working conditions of ECEs, such as employee wages and benefits, are factors which contribute to the professional state of the ECEC field as well as to the quality of service provided in childcare centres [6]. Barnett [7] highlights the following items as areas to focus on when policymakers and educators consider early childhood professionalization: "teacher qualifications, professional development, certification regulation, wages, and benefits, and teacher preparatory programs" [7]. [8] describes professionalism as a method of improving the status, salary, and conditions of the occupational group, in this case ECEs. These all can be identified, also, as indicators for the quality of ECEs' working conditions.

A childcare centre's auspice, or a centre's ownership, and related financial decisions about funding structures and budgeting, are major distinguishing factors between for-profit and nonprofit childcare centres [9]. The financial decisions a centre makes when allocating funds demonstrates the areas in which they place the most value. Full-time ECEs see firsthand the results that financial decisions made at the administrative level have in the centre; it is paramount, then, to listen to ECEs who have had experience in both for-profit and non-profit sectors, and the differences they perceive between these sectors.

Does a funding structure of a childcare centre and its auspice have an effect on the professional state of its ECEs? In other words, in what auspice does professionalism flourish and why? This is analyzed through the lens of the working conditions provided to ECEs. The purpose of this research is to examine ECEs' perceptions of differences in working conditions between for-profit and non-profit sectors (excluding the municipal sector) in the Greater Toronto Area (GTA). 


\section{Literature Review}

\subsection{Different Ways in Which Childcare is Funded}

There are differences with funding sources and governing structures [10], depending under which auspices a childcare centre operates. Non-profit childcare centres are funded by multiple sources: parent fees, donations, and the varying forms of provincial/territorial financial assistance (i.e. grants, subsidies, etc.). In contrast, the majority of funds in for-profit childcare centres come from parent fees. Although some for-profit centres receive provincialterritorial assistance, it is a smaller percentage of their revenue. In addition, for-profit centers cannot accept charitable contributions [11]. Helburn [11] found that the ownership structure of a childcare centre, or its auspice, is an important factor that can have an effect on the organization's resource allocation. [12] found that in Canada, non-profit and for-profit centres allocated different proportions of their budget to different expenditures.

Childcare corporatization refers to a rapid expansion and an escalation in market share of childcare services owned and/or operated for profit by public companies, many of which are listed on the Toronto Stock Exchange (TSX) [4]. Childcare corporations have a duty to generate financial returns to shareholders, and in so doing must comply with additional financial constraints, which can be seen in the allocation of childcare centres' budgets [13]. Reaping a profit must be a motive for for-profit administrators to make their business beneficial for both investors and owners.

Moss [1] has explained that childcare is changing from being viewed as a service to being viewed as a commodity from which to profit. Non-profit childcare centres, in contrast, do not view childcare as a commodity. Non-profit organizations cannot reap a benefit or distribute profits from their organizations. Therefore, researchers found that non-profit childcare centres are less likely to cut costs because they lack the profit motive ([14]; [11]; [13]; [19]). Helburn's [11] study revealed that, as opposed to for-profit centres, non-profit centers with extra resources used these resources to improve quality. When considering Helburn's findings, one might assume that a portion of these extra resources could be put toward improving the quality of ECEs' working conditions, through increased wages, benefits, and compensated professional development opportunities.

\subsection{Differences in Working Conditions in For-profit and Non-profit Childcare Centres}

When it comes to working conditions, very few research studies differentiate between the for-profit sectors and non-profit and even fewer studies ask about ECEs' personal experiences. Therefore, using the key findings from studies which evaluated the quality of working conditions identified in Doherty et al.'s [12] Canadian 'You Bet I Care' study, the researcher has compiled a list of key indicators which will be used in this study to evaluate ECEs' perceptions of the quality of working conditions in a childcare centre. Thus my definition of the term working conditions will be based on the following indicators: staff qualifications, professional development opportunities, wages, benefits, and turnover. Whitebook, Howes, and Phillips' [15] also define 'adult work environments' as factors which include aspects of a childcare center's operation that impinge directly on the quality of the day-to-day demands of working in the center. This definition has been helpful in identifying other indicators that impact on ECEs day-to-day experiences.

Researchers have suggested that elements such as a centre's auspice, variations in clientele, funding sources, regulatory accountability, governing and administrative structures may have an effect on working conditions [6]. With that said Harwood, Klopper, Osanyin, and Vanderlee [17] notes that, along with clear divisions between ownership, a resulting divide exists between the corresponding policies, educators' qualifications, trainings, equity and quality, and conceptualizations of professionalism.

Studies that compare the quality of working conditions between for-profit and non-profit centres provide insight into the value an auspice places on professionalizing the field of ECEC, which, in turn, is demonstrated by the dynamics of a childcare centers' funding structure. Most studies have found that nonprofit centres provide better wages, better benefits, more professional development opportunities and thus have a lower turnover ([14]; [12]; [13]; [6]; [19]; [10]). Most of the research confirms that non-profit childcare centres provide ECEs with better working conditions.

In their studies, Doherty et al, [12] and Whitebook and Sakai, [15], make the important observation that the participants and centres studied were from different locations (i.e. provinces, states, etc.), which may mean different legislations and restrictions for for-profit centres [9;11]. Therefore, all eligible participants were required to have worked in the same jurisdiction to ensure that the same laws, regulations, and restrictions were mandated for all for-profit centres and non-profit centres where ECEs were employed.

Doherty's et al. [12] study is one of the few Canadian studies. This small-scale study will investigate whether improvements in working conditions have been made since 2000. Moreover, ECEs' perspectives and experiences of the working conditions between sectors is a view often neglected 
in the debate between for-profit and non-profit childcare centres. Highlighting ECEs' perceptions may produce data that is unique, while validating ECEs as experts and professionals within the field.

\section{Methodology}

As professional members of the childcare community, ECEs' voices should be heard and considered when decisions are made affecting them [8]. ECEs work in childcare centres on a daily basis and, as a result, can bring an important perspective and a relevant local knowledge to the discussion around childcare practice and policy [1]

This study used a qualitative approach in order to gain a deeper and richer understanding of each participant and their experiences. Four participants were selected for this study. This small sample size is sufficient to build a preliminary understanding of perceived differences between working conditions in the for-profit and non-profit childcare sector. As a result any findings derived from this research needs to be further examined in light of the number of participants interviewed for this study. Therefore, in future researchers may attempt to duplicate this study with a larger sample size. A semi-structured interview tool was devised for data collection since a structured, closed-ended set of questions would fail to adequately highlight the experiences and perceived differences in working conditions of ECEs. Patterns and themes were drawn from participants' responses.

\subsection{Participant Profiles}

Information was gathered through the interview process which provided a brief background of each participant's experience in the field of childcare and the respective sectors. The information provided for this article is limited in an effort to maintain confidentiality. Pseudonyms will be assigned to each participant.

Participant A, Ashley, had a combined seven years' experience as a full-time ECE. Ashley has spent one year in two different for-profit centres combined, which she reports were both chain owned/franchises. The remaining six years of her experience have been spent in a unionized non-profit childcare centre. Participant B, Brittney, worked in two for-profit childcare centres, both chain owned/franchises, from 2005 to 2008. Brittney then worked for a few non-profit childcare centres while she pursued higher education. Participant C, Cathryn, for six years worked in a private childcare centre owned by a company. Cathryn then worked for three years at a college-affiliated childcare lab school, which was unionized. Participant D, Diana, is a landed immigrant who worked for three years in a privately owned, Canadian for-profit childcare centre. Diana now works at a unionized, college-affiliated lab school. She has worked at this non-profit centre now for six years.

\section{Discussion}

Four ECEs who have worked in both for-profit and non-profit childcare centres reported vast differences in working conditions between sectors. The following discussion will identify research consistent or inconsistent with this study's findings, as well as discuss the impact that the variations between for-profit and non-profit have on the efforts put towards professionalizing the field of ECEC.

\subsection{Theme 1: Material Conditions}

Most ECEs are women in what has traditionally been viewed as a woman's field. The public and consumers continue to question the use of the term professional in discussion of ECEs. Despite the lack of understanding, social respect, and value of the ECEC field, ECEs continue to work towards developing a professional status. In reality, efforts towards attaining professional status for ECEs inevitably connect to economic issues, in particular compensation in the form of wages and benefits.

Benefits are an important factor to consider when discussing ECE working conditions. In a field where employees are earning lower wages, benefits can be viewed as an addition to an ECE's individual salary as well as "provide a measure of longer-term security" [12]. Consistent with Mullis et al. [6]'s results, this study found that non-profit childcare centres were more likely to provide health care benefits to their ECE employees. Two of the four participants interviewed did not receive benefits for health care services from their for-profit childcare centre.

Participants indicate that wages were a relevant and meaningful issue to them. The participants' spontaneous focus on wages reinforces the importance of wage differentiation to each one of them. ECE practitioners are significantly underpaid compared to other occupations which require similar educational and personal backgrounds [11], which calls into question the professional status equated to the ECEC field. ECEs that were interviewed reported receiving significantly lower wages in for-profit childcare centres, which is consistent with research that found ECEs received higher wages in non-profit childcare centres ([14]; [12]; [13]; [6]; [18]; [10]).

With the ultimate goal of yielding a profit, there is often no reference or consideration to democratic political practice. Cuts to operating costs, including cuts to ECEs compensation, have an inevitable effect on ECEs, and the ECE profession as a whole, yet their voices are rarely considered in such initiatives. As a professional group ECEs have a responsibility to engage in decision-making debates surrounding 
issues concerning their work ([8]; [7]). Corporatized childcare centres, that are running a business, are required to accommodate the needs of owners and shareholders first [9], all the while ignoring all efforts towards achieving a professional status, by not considering or valuing the voice of ECEs as the experts.

The ECEs interviewed reported that the for-profit childcare centres they worked at tended to hire employees who held the bare minimum of credentials. According to Ashley, at times the minimum age of 18 was the only requirement. In this study, non-profit centres were found to employ ECEs with significantly higher levels of education in comparison with the forprofit centres. This study validates both the results of Doherty et al., [12] and and Sosinsky, Lord, and Zigler., [10] who found a relationship between a sector type and ECEs qualifications. Professionalism is often understood as a practitioner with substantial acquisition of specialist knowledge/qualifications, as well as the ability to meet high standards [1]. The findings in this study demonstrate that for-profit childcare centers were more lackadaisical when it came to educational qualification requirements in their employees. This, in turn, demonstrates a devaluing for the professionalization of the ECEC field.

It is important to note that for a centre to hire highly educated staff they would likely need to pay higher wages in order to retain these employees. Highly educated staff are more likely to leave a job if they earn lower wages [15]. In this study, a relationship between qualifications and job retention was evident. Generally, ECEs with more education will not be satisfied receiving a minimum wage. As a result, these highly qualified ECEs, who would help to increase the professionalized perception of the ECEC field, may look for employment elsewhere [1].

This study's findings are consistent with Mullis et al. [6]'s results that found that non-profit childcare centres offered and provided more professional development opportunities than did for-profit childcare centres. Participants expressed that when they worked for for-profit childcare centres, professional development opportunities were not mandatory nor were they compensated, as opposed to their non-profit employers.

Professional development was particularly meaningful to ECE participants in this study. All participants, unprompted, addressed the issue of professional development in their responses to openended questions. Indeed, Brittney made an attempt to request professional development opportunities in her for-profit centre but was denied it. As a consequence, she attended a workshop on her own time and with her own resources.

Martin et al. [5] found that ECEs who received relevant and applicable training felt more qualified and perceived themselves as more professional.
Doherty et al. [12] validates that ECEs should continue to develop their skills and build on their knowledge beyond what they were initially taught; according, to these researchers, "life-long participation in professional development is necessary to expand skills and knowledge, to develop fresh ideas, and to refine practice" (p.43). Although ECEs are willing to attend professional development courses, the extra time and financial resources needed may be seen as a considerable deterrent. Auspices that support ECEs in completing continued professional development highlight a value for knowledge and aid in developing a professional status for ECEs.

Based on these findings it may seem as if the importance of professionalism is undervalued in the for-profit sector. ECE participants drew attention continuously to the fact that owners are completely motivated by making a profit. Participants suggest that owners have created a culture of compromise and mediocrity within their programs and within the field of ECEC. For-profit owners frequently hire ECEs with lower qualifications; when hiring ECEs with minimum credentials, owners in a for-profit centre can justify offering their staff minimum wages and benefits. Along the path of mediocrity for-profit owners may suggest professional development opportunities at the expense of the ECE, because workers are expected to pay and use their own time.

\subsection{Theme 2: Non-Material Conditions}

The psychological well-being of ECEs was found to be a relevant factor to include as an indicator of working conditions, and their perceptions of themselves as professionals. Rodgers and RaiderRoth [16] describe the role of 'presence' in professionalism "as a state of alert awareness, receptivity, and connectedness to the mental, emotional, and physical workings of both the individual and the group in the context of their environment, and the ability to respond with a compassionate best next step" (p. 265). The psychological impact experienced by ECEs can be recognized as a working condition, since it too has an effect on how ECEs perceive themselves as professionals within their respective auspice.

While it is not listed as a working condition in other research, the research findings seem to indicate that support given to ECEs was important, because without it ECE participants reported feeling as if they were alone. Participants reported not receiving supports as ECEs when employed in for-profit childcare centres compared to the support they felt from managers in their non-profit childcare centres. Ashley felt unsupported when she went to ask her forprofit employer for help and was told to just keep doing what she had been doing. Ashley did not know what to do and felt like she had no one to turn to. [16] highlight the importance of connectedness between 
the mental, emotional, and physical with the group to an individual ECE's sense of presence in professionalism. Staff collaboration and the building of a sense of community among the staff within a centre help contribute to ECEs' psychological wellbeing and perception of themselves as professionals $[5]$.

A sense of community within the work environment as well as how ECEs related and interacted with their colleagues and clientele was reflected in ECEs' desire to perform at a high level, and to be willing to put the effort forward that's required to achieve the goal of professionalism [5]. [12] addresses a sense of community and collaboration as important since it "enables staff to socialize informally, to give each other support, to confer about problems, and to exert some influence on decision-making in the centre" (p.32). The research findings seem to indicate that the sense of community to be relevant to the ECEs interviewed. Cathryn expressed that she enjoyed the positive environment and the many events that were put together, since it brought the staff together as a team. On the other hand, participants reported more of a competitive and disjointed community in their for-profit childcare centres than in their non-profit childcare centres.

A poor work environment can impede the psychological well-being of an ECE and the resulting sense of community in their for-profit work environment. Cathryn and Diana described their work environment as very competitive. Cathryn perceived her role in her for-profit working community as insignificant, and as a result felt as she held no value and had no decision making power. There is a connection between professionalism and one's ability to exercise a certain level of autonomy, which was not evident within two of the participants' for-profit childcare centres.

Participants reported having more decisionmaking power and autonomy when working in their non-profit centres than in their for-profit centres. Decision-making opportunities enhanced ECEs' working conditions because they feel respected and valued. At times ECEs may feel insecure about their professional status since they often perceive themselves as powerless against authority. ECEs need to gain confidence and value their perspectives as professionals. ECEs need to recognize that they bring a critical perspective to the democratic forum [1] as professionals and experts within the ECEC field. When for-profit childcare centres' owners negate to provide decision-making and autonomy opportunities they fail to validate ECEs as knowledgeable and competent professionals in their field.

My findings indicate that participants felt valued as professionals in their non-profit childcare centres, which seemed to be in connection with the level of autonomy given to them. Diana mentioned that the owner at her for-profit centre would come into the room and watch her all the time and ask her to justify and validate her every practice and action. Diana felt very depressed and disrespected because, although she knew her job and what was expected of her, she was constantly supervised. "The variety of ways in which care is understood by educators themselves becomes a salient issue in defining professionalism" [17]. In such a model, ECEs are trusted as professionals, providing them greater agency in how they guide, judge, and limit themselves [17]. Rather, in Diana's account, she was subjected to what Osgood (2006) describes as "construction of professionalism within early years education, [where educators are subject] to a disempowering, regulatory gaze in the name of higher standards" (p. 7). Referring to Osgood's definition, Diana was viewed and treated as a professional within her non-profit childcare centre, as opposed to within her for-profit childcare centre.

All four participants in this study resigned from a for-profit centre, and their reasons for resigning had to do with one or more working condition. This finding is similar to Mullis et al. [6], Nuttall, [18], and Sosinsky et al. [10] who found the turnover rates for ECEs in for-profit centres to be higher. ECEs are committed to their profession and they understand the effects and consequences when, and if, they leave a childcare centre [5]; therefore, generally when an ECE does decide to leave it, would be for an issue they strongly believe in.

While working in for-profit centres, the participants in this study viewed their positions as temporary. The temporary nature of these positions likely is a reflection of or has an impact on their perceptions of themselves as professionals. Langford found that many graduates were not willing to become on the floor ECEs, or to stay within these positions, as the workforce is marginalized economically, socially and politically. Martin et al. [5] identifies that among professionalism indicators, an ECE's sense of commitment demonstrated the most significant relationship to feeling like a professional. Knowing that one is not in a work environment long-term may inhibit and minimize the efforts one may put forward in a job, as well as inhibit their self-perception as a professional, which in term reflects on the professionalism of the ECEC field itself.

High turnover rates can impede and even jeopardize the operation of any childcare center. The abrupt departure of an ECE can disrupt child/family and caregiver relationships [10]. The resignation of a primary caregiver can compromise a child's developmental growth ([10]; [15]) as well as the view of professionalism within our field. This study's findings were consistent with those of Mullis et al. [6], Nuttall [18], Sosinsky et al. [10], and Whiteboook et al., [15], who found that turnover rates are significantly higher in for-profit centres. The high turnover rates found in for-profit centres may lead to 
overall negative effects on the quality of service and quality of working conditions provided.

In conclusion, the psychological effects when working in for-profit childcare centres were reported by the ECEs interviewed for this study to be more negative compared to more positive psychological effects when working in non-profit childcare centres.

\section{Looking Ahead: Recommendations}

In this study, it is found that for-profit childcare centres tend to provide inadequate and poor quality working conditions for their ECEs. However, readers must recognize that, although this may shed a favorable light on the working conditions non-profit childcare centres are reported to have provided, this is a false façade. There needs to be "an increasing recognition that the work is complex" [1]. For all ECEs working in for-profit and non-profit childcare centres, fair material and non-material compensations should be provided in an effort to retain competent, skilled and quality ECEs in the childcare field.

A provincial/territorial salary grid should be implemented to provide better pay and regulate scheduled raises. A salary grid would illuminate wage disparities among staff with similar qualifications and experience levels. Improving and regulating the types of benefits provided to ECEs would also help to retain ECEs within the field of childcare.

Moss [1] argues that based on their local knowledge, ECEs should be invited to engage in decision-making about their work environment of a childcare centre, since they are the professionals within the ECEC field. Moriarty [8] agrees with Moss [1], suggesting that in order to professionalize the field of ECEC, we must adopt an understanding of professionalism that calls for ECE practitioners to take more complex and democratic roles. Democracy calls for ECEs to be included and involved in decisions that directly affect them (i.e., working conditions) as well as broader issues surrounding their work. Democratic political practice involves a collective decision-making process that should involve policy makers, owners, managers, and ECEs.

Mandatory and compensated professional development opportunities should be offered to ECEs by their centres. Owners and managers should compensate professional development fees, tuition, and time taken off by ECEs. With these further qualifications perhaps managers, owners, policymakers, and Canadians as a whole, would find a new value in ECEs and view them more as professionals.

With the aim of achieving professional status within the ECEC field Buysse, Winton, and Rous [20] suggested that a consistent and mandated definition of professional development be created, laying out a set of professional development competencies or standards. Martin et al. [5] agreed with Buysse et al.'s
[20] point when they stressed the importance of having suggested "training recommendations to create a better knowledge of the 'what' the child care workforce should know about children and families" [20] when moving towards early childhood professionalization.

\section{Conclusions}

This research is framed around the belief that ECEs' experiences should be viewed as a valued source of knowledge that can contribute and impact decisions being made on their behalf. Therefore, four ECEs were interviewed and through a qualitative analysis process, differences in working conditions between for-profit and non-profit centres were found. The themes which emerged from the participants' voices were not only consistent with previous research findings but also identified new findings, such as the non-material conditions, the psychological well-being of ECEs.

Through listening to the experiences of the ECEs, the researcher was surprised that all ECEs had resigned from for-profit childcare centres. The researcher was also surprised at the extent to which the psychological impacts (referred to as non-material conditions) of working in each sector had on their working conditions. However, this research is only a preliminary examination of the perceived differences between the working conditions of ECEs in both the for-profit and non-profit childcare sector. As a result, additional research is required in an effort to further confirm the divide between the working conditions in each sector. The researcher has proposed further research that may further substantiate these surprisingly new findings.

Doherty et al. [12] state that, "how teaching staff feel about child care as a career directly influences both how they respond to children and their likelihood of remaining in the child care field" (p.85). The early childhood workforce is growing and for-profit childcare centres are expanding, so ECE working conditions are becoming an impressing issue, especially since we know the working conditions of ECEs have been demonstrated, through research, to correlate to the quality of service provided to children and their families. This issue, therefore, "needs to encompass restructuring and rethinking" [1] in an effort to ensure improved working conditions for early childhood educators who care for and educate young children.

\section{References}

[1] Moss, P., (2006). Structures, understandings and discourses: possibilities for re-envisioning the early childhood worker. Contemporary Issues in Early Childhood, 7(1), 30-41. 
[2] Child Care Human Resources Sector Council, (2009). A portrait of Canada's early childhood education and care (ECEC) workforce (2009). Canada: Author.

[3] Service Canada, (2013). Service Canada - People Serving People. Retrieved June 15th, 2014 from http://www.servicecanada.gc.ca/eng/qc/job_futures/statisti cs/4214.shtml. (Access date: 12 March 2015).

[4] Canadian Union of Public Employees (CUPE), (2012). The pursuit of profit in Ontario child care: risky business for parents and government. Retrieved February 2nd, 2012, http://cupe.on.ca/a4488/Ontario\%20Childcare\%20At\%20R isk.pdf. (Access date: 7 May 2015).

[5] Martin, S., Meyer, J., Jones, R., Nelson, L., and Ting, L., (2010). Perceptions of professionalism among individuals in the child care field. Child Youth Care Forum, 39, 341349 .

[6] Mullis, A., Cornille, T., Mullis, R., and Taliano, K., (2003). Childcare center directors' perceptions of their work environments: a comparison of for-profit and non-profit programs. Early Child Development and Care, 173(5), 545556.

[7] Barnett, R., (1997). Towards a Higher Education for a New Century. University of London, Institute of Education.

[8] Moriarty, V., (2000). Early years educators in finland and england: Issues of professionality. International Journal of Early Years Education 8(3), 235-241.

[9] Friendly, M., and Prentice, S., (2009). About Canada: Childcare. Fernwood Publishing: Halifax.

[10] Sosinsky, S. L., Lord, H., and Zigler, E., (2007). Forprofit/non-profit differences in centre-based child care quality: results from the national institute of child health and human development study of early child care and youth development. Journal of Applied Developmental Psychology, 28(1), 390-410.

[11] Helburn, S. W., (1995). Cost, quality, and child outcomes in child care centers. Technical report. Denver: Department of Economics, Center for Research in Economics and Social Policy. University of Colorado at Denver.

[12] Doherty, G. Lero, S. D., Goelman, H., LaGrange, A., and Tougas, J., (2000). You Bet I Care Study. Centre for Families, Work, and Well-Being. University of Guelph: Ontario.

[13] Mukerjee, S., and Witte, D. A., (1993). Provisions of child care: cost functions for profit-making and not-forprofit day care centers. The Journal of Productivity Analysis, 4(1), 145-163.

[14] Cleveland, G. and Krashinky, M., (2004). The quality gap: A study of nonprofit and commercial child care centres in Canada. Toronto: University of Toronto at Scarbrough, Division of Management.

[15] Whitebook, M. and Sakai, L., (2003). Turnover begets turnover; an examination of job and occupational instability among child care center staff. Early Childhood Research Quarterly, 18(1), 273-293.

[16] Rodgers, C. R., and Raider-Roth, M. B., (2006). Presence in teaching. Teachers and Teaching: Theory and Practice, 12(3), 265-287.

[17] Harwood, D., Klopper, A., Osanyin, A., and Vanderlee, M. L., (2013). 'It's more than care': early childhood educators' concepts of professionalism. Early Years, 33(1), 4-17.

[18] Nuttal, G. J., (1991). A Comparison of the employment experiences of childcare workers in non-profit and privately-owner childcare centres: some preliminary findings. Early Childhood Convention: New Zealand.

[19] Phillips, A. D., (1992). The social policy context of child care effects on quality. Journal of Community Psychology, 20(1), 25-51.

[20] Buysse, V., Winton, P. J. and Rous, B., (2009). Reaching consensus on a definition of professional development for the early childhood field. Topics in Early Childhood Special Education, 28, 235 - 243. 